\title{
Mathematics Teachers Training Problems in the Context of the of New Educational Standards Introduction
}

\author{
Tatiana Gordienko ${ }^{1 *}$, Tatiana Bezusova $^{2}$, Anna Mezentseva ${ }^{3}$ Haykaz Hovhannisyan ${ }^{4}$ \\ ${ }^{1}$ Crimean Engineering and Pedagogical University, 295015 Simferopol, Russia \\ ${ }^{2}$ Perm State University, 614990 Perm, Russia \\ ${ }^{3}$ Black Sea Higher Naval School named after P. S. Nakhimov, 299040, Sevastopol, Russia \\ ${ }^{4}$ Yerevan State University, Faculty of Philosophy and Psychology, 0025 Yerevan, Republic \\ of Armenia
}

\begin{abstract}
The article is devoted to the future mathematics teachers training problems. The problems range of this educational process is represented by the following components: applicants with a low level of mathematical training, insufficient hours for fundamental mathematical disciplines in curricula, reorganization of the educational process with a focus on expanding electronic content. The insufficient number of hours devoted to the study of mathematical disciplines leads to the fact that students do not form subject knowledge. The article outlines ways to eliminate problems in the future mathematics teachers preparation: the propaedeutic courses introduction, the structural and didactic schemes development in the main mathematical sections, the disciplines integration, the system use of practical tasks, the preparing students holistic model for the use of information and communication technologies creation. The results of the training teachers experience in one domestic educational institution of higher education are presented. In accordance with which, such components as sufficient pre-university preparation, integration of disciplines, schematization of mathematical content, creation of conditions for combining the logical and figurative components of the students' mathematical culture, and informational competence of students become necessary in the structure of building the educational process.
\end{abstract}

\section{Formulation of the problem}

* Corresponding author: tatgordienko@gmail.com 
Mathematical education plays a special role in the implementation of the tasks facing Russia, defined by the Strategy of scientific and technological development of the Russian Federation, the program Digital Economy of the Russian Federation. The educational system is undergoing revolutionary changes that require new ideas and suggestions on educational models and technologies. The mathematics importance in this process cannot be overestimated, mathematical models are the basis for the creation of new algorithms, architectures and even paradigms in the field of information technology. It is necessary to pay attention to the study of mathematics at all educational levels. Consider this problem from the perspective of training future mathematics teachers. The new FSES $3++$, unlike the previous versions of FSES $3+$, disclose the content of only universal and general professional competencies, and their contents are invariant for all profiles of the same training area. The main universal competencies categories include: systemic and critical thinking, project development and implementation, teamwork and leadership, communication, intercultural interaction, self-organization, life safety [1]. General professional competencies affect all aspects of the educational activity organization: legal and ethical professional activity foundations, basic and additional educational programs development, students joint and individual activities, monitoring and evaluating the educational results formation, etc. As before, specific skills, abilities and experience have not been affected activities that graduates in specific subject areas of knowledge should master.

In the Federal State Educational Standard of Higher Education in the direction of preparation 44.03.01 Pedagogical education (qualification (degree) bachelor) [1] there is no subject component. The federal educational standards content for mathematical profile graduates has no indicators defining the spectrum and depth of mathematical knowledge, skills and experience of the mathematical methods field of application. It is also noteworthy that the new $3++$ standards strictly reduce the list of indicators and the legal framework (professional standards, employers requirements), which must serve as initial data for the development of both personal competencies as a whole and indicators to them. For comparison, the content of $3+$ standards contains the wording of all types of competencies (general cultural, general professional and professional), but the subject component is also absent.

\section{Problem}

New educational standards do not affect the subject matter, require an increase in hours for students to work independently, and significantly increase the amount of time devoted to practice. Under the conditions of the Federal State Educational Standard, independent work is called upon not only to consolidate subject knowledge, but also to enable the student to master the types of activities characteristic of a future profession. An increase in the share of students' independent work entails a different methodology for organizing lecture and practical classes. In this regard, lectures are becoming more and more of a review nature, and practical classes are features of seminars.

A clear statement of the purpose of the article: to outline the problems range in the preparation of future mathematics teachers and outline ways to address them.

The main material presentation, which is a critical analysis of research and scientific publications devoted to this problem. Analyzing the scientific and methodological literature on the mathematics training teachers problems, one can notice two research areas. One of them presents the methodological techniques analysis for specific mathematics sections studying. For example, elementary mathematics (Khrapay O.I. [2], Burchak S.A. [2], Melnikov R.A., Elchaninova G.G. [3]), algebra and number theory (Loginovskikh L.M., Tyshuk L.N. [4]), empirical data statistical analysis methods (IP Lebedeva [5]). The second 
direction is represented by works that reveal the preparing a mathematics teacher problems from the perspective of modernization and a systems approach (VassalatiyYu.V. [6], Dalinger V.A. [7]).In the article VassalatiyYu.V. [6] describes the mathematics teacher competency model, defines the readiness concept of future mathematics teachers to organize the independent high school students work in the context of specialized education. The educational process in a higher pedagogical educational institution is also analyzed and new pedagogical conditions for improving the process of training future mathematics teachers are proposed.

Following the views of Daliner V.A. on the professional future teachers training problem subject, the following will be attributed to the disadvantages of the mathematicians training system for teachers: there is a tendency to reduce the hours volume for fundamental mathematical disciplines, which leads to a superficial knowledge of the basic mathematical disciplines content; low passing scores of the Unified State Examination in pedagogical educational organizations of higher education (OEO) determine the contingent of freshmen with poor mathematical training; the study of mathematical disciplines in higher education occurs in isolation from the school component of mathematical education [7].

One of the main points to modern educational standards is the disproportionality of the hours number devoted to the mathematical disciplines study and the mathematical knowledge amount that students must master, both for the successful implementation of their professional activities and for achieving an adequate level of mathematical culture.

Analyzing the curriculum for the bachelors preparation in the Pedagogical Education direction in dynamics over several years, you can notice a tendency to reduce the hours number in mathematical disciplines. As proof of the aforesaid, we note that prior to the introduction of new FSES in the teaching mathematics teachers process, all the major mathematical disciplines (for example, mathematical analysis, algebra, analytical geometry) were allotted 144 class hours per year, with at least two academic years for each discipline. In today's curriculum, classroom hours have become incomparably smaller. The course Mathematical Analysis in accordance with the curriculum now involves training for one academic year. In the first trimester, hours are distributed as follows: 28 lectures and 14 practical, in the second trimester -14 lectures and 28 practical, and in the third trimester, 14 lectures and 14 practical classes. After a year of study, the student passes the final exam. In addition, it is necessary to note the trend towards the integration of disciplines.

In the training of qualified personnel in the conditions of the PSA, the issue of recruiting applicants is of particular importance. Today's applicants have a low level of knowledge in most cases. In the article by Dalinger V.A. [7] there are examples of freshmen low-level mathematical knowledge.

We highlight the main reasons for the decrease in the level of applicants preparedness in the mathematics field:

1. Low values of annual threshold values for points of the Unified State Exam (USE), and a decrease in the required number of points for admission to the PSL. In almost every fifth institution of higher education, for admission to areas and profiles that are less in demand among applicants, it is enough to only present the minimum threshold scores for all disciplines. Assessing the results of the exam in mathematics at the core level for the 2019 academic year, we note that the average test score in mathematics in 2019 is slightly different from 2018 and 2017 (average test scores for 2017, 2018, 2019, respectively 47.1; $49,8 ; 56.5)$.

2. School graduates simultaneously submit their documents to various higher educational organizations in hotel areas. A prestigious university can increase the score for admission, that is, there is a diversification of the opportunity to get a higher education. The student no longer needs to carefully prepare for the final exams, as among the proposals for 
university entrants there is also a high probability that one can study in the same direction with a low mark threshold, possibly for a fee. The exclusivity of higher education is being lost. Higher education is becoming available.

3. Among the main reasons for the low mathematical training of educational institutions graduates can be identified: lack of self-learning skills among students, a proof culture of statement slack, working culture lack with special literature, large gaps in specific sections of mathematics.

In the context of education digitalization, one of the main directions in the teacher training system in higher education is the development of new information technologies. The subject preparation of the future mathematics teachers is related to the disciplines digitalization of classical mathematics. This process is based on the ability of students to use symbolic computing programs (MatLab, MathCad, Mathematica). However, we have to admit that far from all teachers in the PSE are competent in using mathematical modeling packages. Therefore, they solve serious applied problems and carry out complex calculations without using specialized software. The solution to this problem lies in the introduction of interdisciplinary special courses in the curriculum focused on the visualization of mathematical data, graphing, and the processing of large amounts of experimental data. Such special courses can be taught by two teachers: mathematician and computer scientist.

Since 2012, training has been underway at the Solikamsk State Pedagogical Institute in the direction of 44.03.01 Pedagogical Education. After analyzing the reasons for the decrease in the level of mathematical preparedness of applicants and systematizing our experience for the future mathematics teachers quality training, students are trained according to the following methodology:

1. Before starting the training, an ascertaining section of knowledge is carried out, the results of which show the knowledge level and students skills, which allows you to adjust the content of the course Introduction to Mathematics. The curriculum for the specified training profile contains a propaedeutic mathematical course (Introduction to Mathematics, 3 credits).

2. The material presentation on mathematical disciplines is accompanied by the construction of structural-didactic schemes, which become the basis for the development of supporting abstracts by students on their own.

3. A close interdisciplinary connection between the content of fundamental mathematical disciplines is provided: linear algebra, analytical geometry, mathematical analysis with the theory and technologies of mathematical education. A means for fixing the discovered connections is a reference book, in which related topics are simultaneously recorded from the position of a university and school presentation of cross-cutting mathematical topics.

5. The industrial practice (technological, practical) content is supplemented by tasks related to the study of the information and communication technologies environment (ICT) in an educational institution and work with it. The corresponding profile curriculum contains an optional course focused on the study of the modern multimedia boards use and their software, telecommunication tools in education, etc.

Graduating students in accordance with the requirements of GEF in the direction of 44.03.01 Pedagogical education profile of Mathematics in 2016/2018 passed the interdisciplinary state exam. The tickets for the interdisciplinary state exam had three questions: two questions in mathematics, which reflected the courses content in mathematical analysis, geometry, algebra, and number theory, and one question on the methodology of training and education in the field of mathematics. The results shown by students in the final tests are presented in tables (table 1, table 2, table 3). 
Table 1. The Final Tests Results on the Training Methodology and Education in the Mathematics Field (2016)

\begin{tabular}{|c|c|c|c|c|c|c|c|}
\hline $\begin{array}{c}\text { Answersgeneral } \\
\text { number }\end{array}$ & $\ll 5 »$ & $\ll 4 »$ & $\ll 3 »$ & $\ll 2 »$ & $\begin{array}{c}\text { Absolute } \\
\text { performance, \% }\end{array}$ & $\begin{array}{c}\text { Knowledge } \\
\text { quality, \% }\end{array}$ & Averagerating \\
\hline 12 & 5 & 5 & 2 & 0 & 100 & $83 \%$ & 4,25 \\
\hline
\end{tabular}

Table 2. Final Tests in Mathematics Results (2016/2018)

\begin{tabular}{|l|c|c|c|c|c|c|c|c|}
\hline & $\begin{array}{c}\text { General } \\
\text { answers } \\
\text { number }\end{array}$ & $« 5 »$ & $\ll 4 »$ & $\ll 3 »$ & $\ll 2 »$ & $\begin{array}{c}\text { Absolute } \\
\text { performance, } \\
\%\end{array}$ & $\begin{array}{c}\text { Knowledge } \\
\text { quality, \% }\end{array}$ & Averagerating \\
\hline $\begin{array}{l}\text { The first } \\
\text { question }\end{array}$ & $12 / 6$ & $4 /$ & $2 /$ & $6 /$ & $0 /$ & $100 / 100$ & $50 \% / 67 \%$ & $3,8 / 4$ \\
\hline $\begin{array}{l}\text { The } \\
\text { second } \\
\text { question }\end{array}$ & $12 /-$ & $3 /$ & $4 /$ & $5 /$ & $0 /$ & $100 /-$ & $58,3 \% /-$ & $3,83 /-$ \\
\hline
\end{tabular}

Table 3. Results of answers to the questions in mathematics (differentiated by discipline) (2016/2018)

\begin{tabular}{|l|c|c|c|c|c|c|c|c|}
\hline & $\begin{array}{c}\text { General } \\
\text { answers } \\
\text { number }\end{array}$ & $« 5 »$ & $« 4 »$ & $\ll 3 »$ & $\ll 2 »$ & $\begin{array}{c}\text { Absolute } \\
\text { performance, } \\
\%\end{array}$ & $\begin{array}{c}\text { Knowledge } \\
\text { quality, } \%\end{array}$ & $\begin{array}{c}\text { Average } \\
\text { rating }\end{array}$ \\
\hline $\begin{array}{l}\text { Algebra and } \\
\text { number } \\
\text { theory }\end{array}$ & $8 / 4$ & $3 / 1$ & $1 / 2$ & $4 / 1$ & $\begin{array}{c}0 / \\
0\end{array}$ & $100 / 100$ & $50 \% / 75 \%$ & $3,9 / 4$ \\
\hline $\begin{array}{l}\text { Geometry } \\
\text { Mathematical }\end{array}$ & $6 / 5$ & $2 / 2$ & $1 / 1$ & $3 / 2$ & $\begin{array}{c}0 / 2 \\
0\end{array}$ & $100 / 100$ & $50 \% / 60 \%$ & $3,83 / 4$ \\
\hline
\end{tabular}

The working practice with mathematics students, taking into account the previously described methodology, gives positive dynamics in a qualitative aspect. The ticket structure for the exam in 2018 was changed, a situational task appeared on the methodology of training and education in the mathematics field. Let us present the results shown by students in the final tests in 2018 (table 4). The tickets for the interdisciplinary state exam in the direction 44.03.01 Pedagogical education profile Mathematics had four questions: two questions in mathematics, which reflected the courses content in mathematical analysis, geometry, algebra and number theory, and two questions on the methodology of training and education in mathematics (in including one practice-oriented task).

Table 4. The results of the final tests on the methodology of training and education in the field of mathematics (2018)

\begin{tabular}{|l|c|c|c|c|c|c|c|c|}
\hline & $\begin{array}{c}\text { General } \\
\text { answers } \\
\text { number }\end{array}$ & $« 5 »$ & $« 4 »$ & $« 3 »$ & $\ll 2 »$ & $\begin{array}{c}\text { Absolute } \\
\text { performance, } \\
\%\end{array}$ & $\begin{array}{c}\text { Knowled } \\
\text { ge quality, } \\
\%\end{array}$ & $\begin{array}{c}\text { Average } \\
\text { rating }\end{array}$ \\
\hline $\begin{array}{l}\text { The first } \\
\text { question }\end{array}$ & 6 & 3 & 2 & 1 & & 100 & 83,3 & 4,3 \\
\hline $\begin{array}{l}\text { The second } \\
\text { question }\end{array}$ & 6 & 2 & 4 & 0 & 0 & 100 & 100 & 4,3 \\
\hline
\end{tabular}

The quantitative and qualitative indicators positive dynamics shown by graduates in the final tests indicates the effectiveness of our methodology, namely, the need to identify the pre-university level of freshmen mathematical preparation, and then adjust the course "Introduction to Mathematics" content; the structural and didactic schemes use, schematization of mathematical knowledge; integration of disciplines on similar content 
and (or) methods for solving problems; implementation of specialized software in solving labor-intensive mathematical problems.

\section{Conclusions on this review and the forecast for the further development of the scientific problem}

We note ways to solve the problem of training teachers of mathematics:

1. A tendency towards a decrease in the authority and elitism of higher education has been identified. The problem with the recruitment of applicants becomes the reason that higher education becomes quite accessible for schools graduates with a low level of training. Students of pedagogical universities are schools graduates whose training level does not allow them to continue their studies at another university, where mathematics is a major discipline. It is necessary to create a system of pre-university mathematical applicants training, with the goal of minimizing the gap between the mathematical graduates competencies formed in a general educational institution and the knowledge level and methods of action that students need to successfully master the mathematics content at the university. For example, the subject schools creation at universities, scientific societies, circles, courses in preparation for the exam, where training is carried out by leading employees of mathematical departments.

2. Conducting a stating slice to identify knowledge and skills, and correction within the framework of introductory mathematical courses, allows you to align the initial freshmen training. The mathematical content schematization through the structural-didactic schemes creation, the disciplines integration in content and (or) methods, enables students to master the necessary mathematical knowledge, acquire skills. Independent development of supporting abstracts and work with a reference book, where the connections of related topics from the position of university and school presentation of cross-cutting mathematical topics are recorded, allows you to systematize knowledge, repeat and consolidate the material. This further contributes to the student becoming a highly qualified teacher of mathematics.

\section{References}

1. On the approval of the federal state educational standard of higher education - a bachelor's degree in training 44.03.01 Pedagogical education (Ministry of Justice of Russia, Moscow, 2018)

2. O.I. Snore, S.A. Burchak, Youth introductory. 1(53), 774-777 (2018)

3. R.A. Melnikov, G.G. Elchaninova, Improving Mathematical Education - 2014: Problems and Ways to Solve Materials of the VIII International Scientific and Methodological Conference. 73-76 (2014)

4. L.M. Loginovskikh, L.N. Tyshuk, Variability in teaching the algebra course to mathematics and teachers of mathematics - 2000: Improvement of teaching, education and professional orientation of youth in the system of general and vocational education: abstracts of reports and reports of the regional scientific-practical conference, 55-56 (2000). 5. I.P. Lebedeva, Bulletin of the Tambov University. Series: Natural and Technical Sciences. 4(12), 476-477 (2007)

6. Yu.V. Vassalaty, Collection of scientific papers SWorld. 1(15), 11-19 (2013)

7. V.A. Dalinger, Modern problems of science and education. 1 (2007) 